Preprints are preliminary reports that have not undergone peer review.

They should not be considered conclusive, used to inform clinical practice, or referenced by the media as validated information.

\title{
Measurement of the Active Toxoplasma Retinochoroiditis Lesion Size During the Disease Course With Swept Source Optical Coherence Tomography Angiography: A Retrospective Image Analysis
}

Ferdane Atas ( $\sim$ ferdaneatas@gmail.com )

Dokuz Eylul University Faculty of Medicine: Dokuz Eylul Universitesi Tip Fakultesi https://orcid.org/0000-0002-6743-1142

Mahmut Kaya

Dokuz Eylul University Faculty of Medicine: Dokuz Eylul Universitesi Tip Fakultesi

Tuğçe Toprak

Dokuz Eylul University: Dokuz Eylul Universitesi

Betul Akbulut Yagcı

Dokuz Eylul University Faculty of Medicine: Dokuz Eylul Universitesi Tip Fakultesi

Alper Selver

Dokuz Eylul University Faculty of Engineering: Dokuz Eylul Universitesi Muhendislik Fakultesi

Ali Osman Saatci

Dokuz Eylul University Faculty of Medicine: Dokuz Eylul Universitesi Tip Fakultesi

\section{Research Article}

Keywords: Retinochoroiditis, optical coherence tomography, optical coherence tomography angiography, toxoplasma retinochoroiditis

Posted Date: April 12th, 2021

DOI: https://doi.org/10.21203/rs.3.rs-339254/v1

License: () (i) This work is licensed under a Creative Commons Attribution 4.0 International License. Read Full License

Version of Record: A version of this preprint was published at International Ophthalmology on July 23rd, 2021. See the published version at https://doi.org/10.1007/s10792-021-01985-w. 


\section{Abstract \\ Purpose}

To measure the lesion size reduction in eyes with active toxoplasma retinochoroiditis during the disease course with swept- source optical coherence tomography angiography (SS-OCTA).

\section{Methods}

We retrospectively analyzed the chorioretinal lesion size in a group of 14 eyes with a single active toxoplasma retinochoroiditis lesion.SS-OCTA was performed at the baseline and follow -up in all eyes. The $6 \times 6 \mathrm{~mm}$ choriocapillaris slab images were evaluated with an image analysis (Matlab). The number of black and white pixels in a $1500 \mu \mathrm{m}$-diameter circle centered on each active lesion was counted at the time of baseline examination and at the first follow-up visit when the chorioretinal scar formation was noticed.

\section{Results}

Fourteen eyes with a single active toxoplasmosis retinochoroiditis lesion were included. Ten patients were female and three,male. Mean age was $29.1 \pm 14.9$ years. Active lesions were at the macula in five eyes, at the periphery in six eyes and juxtapapillary in three eyes. At the initial examination lesion area was observed as an area with a decreased flow signal on SS-OCTA.There was perilesional capillary disruption in superficial and deep capillary plexi together with a diffuse capillary network attenuation and non-detectable flow signal zones in the choriocapillaris slabs. In addition to sulfamethoxazole-trimethoprim and azithromycine combination oral corticosteroids were only co-administered in five (35\%) eyes with macular involvement. The chorioretinal scar formation was observed in four to 16 weeks. At the time of inactivity, original lesion was diminished in size when compared to its baseline in all study eyes $(p=0.001)$ with a mean black pixel reduction percentage of $21.8 \%$. The reduction was $15.4 \%$ in eyes with macular lesion, $31.6 \%$ with peripheral lesions and $18.1 \%$ with juxtapapillary lesions $(p=0.001, p=0.032, p=0.028, p=0.043$, respectively). Visual acuity was correlated with black pixel reduction percentage in eyes with macular lesion $(r=0.56, p<0.001)$.

\section{Conclusion}

Active toxoplasma retinochoroiditis lesion size diminished with the healing process as expected and this could be monitorized with an OCTA based image analysis technique. Macular lesions showed less reduction in lesion size despite the addition of oral corticosteroids in contrast to peripheral and juxtapapillary lesions.

\section{Introduction}

Ocular toxoplasmosis is the most common cause of posterior infectious uveitis almost worldwide. In a nationwide web-based registry of uveitis patients that was carried out by the Uveitis and Behcet disease Division of Turkish Opthalmological Society 761 of 4863 patients $(15.6 \%)$ had infectious type of uveitis and nearly half of these patients (343 patients, $45 \%$ ) had toxoplasma retinochorioditis [1].

The common presenting feature of acute ocular toxoplasmosis is a single or multiple focal whitish retinochoroiditis area or areas with fluffy borders mostly at the vicinity of a neighbouring chorioretinal pigmented scar together with a various degree of vitritis mostly condensed on top of the lesion. [2, 3] Histologically, almost all retinal layers were affected but the greater impact was on the deep retina and photoreceptors $[4,5]$.

Optical coherence tomography angiography (OCTA) provides a detailed high-resolution images with in-depth visualization of the superficial capillary plexus (SCP), deep capillary plexus (DCP) and the choriocapillaris (CC), and allows us to visualize the microvascular abnormalities in detail. It is possible to image the retinal and choroidal vascular layers in depth when compared to dyebased angiographies $[6,7]$.

In this study, we aimed to measure the active and then the inactive toxoplasma retinochoroiditis lesion size with SS- OCTA and to see the effect of oral steroid addition to anti-toxoplasma therapy on the lesion size in eyes with a single active toxoplasma retinochoroiditis 
lesion.

\section{Methods}

We retrospectively reviewed the medical records of a total 18 consecutive patients with a single active toxoplasma retinochoroiditis lesion examined between January 2018 and February 2020 at our department. This study was driven in accordance with the Declaration of Helsinki, current Turkish legislation and with the approval of local ethics committee (Approval ID: 2021/04 - 01).

Complete past medical and family history was obtained. Full ocular examination including visual acuity evaluation, intraocular pressure measurement, slit-lamp biomicroscopy and dilated fundus examination was performed in all cases. All clinical descriptions were made according to Standardization in Uveitis Nomenclature (SUN) criteria[8]. At baseline, SS-OCTA examination (DRI OCT Triton Plus ${ }^{\circledR}$ SS, Topcon Corporation, Tokyo, Japan) was performed in addition to ancillary techniques of fluorescein angiogarphy and optical coherence tomography. The commercial DRI Triton instrument operates with a wavelength of $1050 \mathrm{~nm}$ and a scan speed of $100.000 \mathrm{~A}$ scans per second. It has a transversal resolution of $20 \mu \mathrm{m}$ and an axial resolution of $7 \mu \mathrm{m}$. All study eyes were scanned using a $6 \times 6$ $\mathrm{mm}$ image centered on the active lesion site. OCTA images (superficial capillary plexus (SCP), deep capillary plexus (DCP), outer retinal and choriocapillaris (CC) layer slabs) were obtained with the automated layer segmentation performed by the instrument. Measurements were acquired by M.K., F.A., or B.A.. OCT-A examination was performed at least three times and the best one was selected for the image analysis.

Nineteen eyes of 18 patients with a single acute toxoplasma retinochorioditis lesion were examined but a total of 14 eyes of 13 patients were included as good quality OCTA images could not be obtained in the remaining patients. Though the diagnosis of active toxoplasma retinochoroiditis was established on the clinical criteria suggested by Holland et al [9] all patients were also tested for Toxoplasma serology and received a combination of sulfamethoxazole and trimethoprim $(160 \mathrm{mg} / 800 \mathrm{mg}$ twice a day for four to six weeks) and azithromycin (500 mg once a day for nine days). Oral corticosteroid therapy (0,5 mg / kg / day prednisolone equivalent) was added only in patients with sight-threatening macular involvement 48 hours after the administration of antitoxoplasma drugs. Systemic corticosteroid therapy was ceased with a rapid taper before the discontinuation of antiparasitic therapy.

OCTA examination was repeated at each follow up visit.

\section{Image Analysis}

The SS-OCTA of $6 \times 6 \mathrm{~mm}$ the CC slab images were analyzed for each lesion. First, the original gray level images were converted to binary using thresholding. The pixel values below and above the threshold value were assigned as 0 and 1 , respectively. While black pixels represent non-detectable flow signals, white pixels represent healthy retinal tissue [11]. Here, the selection of the threshold value has critical importance on the result. Since the use of a fixed threshold value may cause difficulties due to varying image characteristics across the patients, it was determined automatically with Otsu's method [10]. This method chooses the threshold value that can minimize the in-class variance of black and white pixels. In this respect, the "imbinarize" function of Matlab was used.

After the binarization process, the center of the disease was marked by the clinician. Then, by taking the expert indicated point as the center, a grid of concentric circles of increasing diameter from the center of the lesion site (i.e. 500, 1000, 1500, 2000, $2500 \mu \mathrm{m}$ ) was created to identify the most representative lesion area to analyze. The optimal diameter was chosen as $1500 \mu \mathrm{m}$ to cover all of the lesions (Fig. 1).

Finally, for each circled area, the numbers of 0 (i.e. black) and 1 (i.e. white) valued pixels were calculated. The ratio of the number of black or white pixels to the total number of pixels is defined as the pixel index. The pixel index was counted first at the time of diagnosis and at the first follow up visit when the chorioretinal scar formation was noticed. We considered the lesion as a healed lesion when a pigmented atrophic scar with a relatively sharp margin was observed together with a decreased vitritis.

\section{Statistical Analysis}

All patient data were recorded in the IBM SPSS Statistics (version 24.0, IBM Corp, 66 Armonk, NY, USA) software package and statistical analyses were performed using paired t-test. Normality of the variables was examined using histograms. The correlation was

Page $3 / 10$ 
analyzed using Spearman's correlation coefficient. The results are presented as mean \pm standard deviation, and a $p$ value $<0.05$ was considered statistically significant.

\section{Results}

Fourteen eyes of 13 patients were included in the study. Ten patients were female and three, male. Mean age was $29.1 \pm 14.9$ years (Range 9-59 years). Twelve patients (85\%) had unilateral and one (7.7\%) bilateral involvement. At baseline, overall, the average best corrected visual acuity (BCVA) was $0.3 \pm 0.38$ logMAR (Range; 1.0-0.0). In macular lesions, the baseline BCVA was 0,6 $\pm 0,54$ (Range; $1.0-0.0)$. While seven of 14 eyes ( $50 \%$ ) had mild to moderate anterior inflammation vitritis of $1+$ to $2+$ was present in all eyes. One eye (7\%) experienced an intraocular pressure elevation during the active attack that was successfully managed with a short-term antiglaucoma medication. At the time of initial visit, seven eyes (50\%) had preexisting scars and the remaining eyes had a primary active lesion. Active lesions were at the macula in five eyes, at the periphery in six eyes and juxtapapillary in three eyes. All patients received the above mentioned antibiotic combination. Systemic corticosteroids were administered in five eyes (35\%) with macular involvement. Toxoplasma-specific IgG antibodies were present in all patients, at a mean concentration of $26.4 \pm 6.4 \mathrm{IU} / \mathrm{ml}$ (Range, 10-200 IU/ml). Specific lgM antibody was detected only in a single patient. Mean duration of follow-up was 8,50 $\pm 4,16$ weeks (Range 4-16 weeks). At the initial examination, SS-OCTA showed a lesion area with a decreased flow signal in SCP, DCP and CC segmentation. There was perilesional capillary disruption in superficial and deep capillary plexus layers together with a diffuse capillary network attenuation and non-detectable flow signal zones in the CC slabs. The chorioretinal scar formation was observed between four to 16 weeks (Mean; 8,50 $\pm 4,16$ weeks). At the time of final measurement, active lesion size got smaller when compared to baseline in all study eyes $(p=0.001)$. The final mean BCVA was $0.15 \pm 0.28$ (Range; 1.0-0.0) logMar. In eyes with macular lesions, the final BCVA was 0,36 $\pm 0,40$ (Range 1.0-0.0). The chorioretinal scar formation was observed in a time frame of four to 16 weeks (Range; $8,50 \pm 4,16$ weeks). At that time, active lesion size got smaller when compared to its baseline in all study eyes $(p=0.001)$ with a mean black pixel reduction percentage of $21.8 \%$ (Fig. 2). The reduction was $15.4 \%$ in eyes with macular lesion, $31.6 \%$ in eyes with peripheral lesion and $18.1 \%$ in eyes with juxtapapillary lesion ( $p=0.001, p=0.032, p=0.028, p=0.043$, respectively). Visual acuity was correlated with black pixel reduction percentage in eyes with macular lesion $(r=0.56, p<0.001)$.

The findings related to clinical findings and the results of Matlab analysis for all eyes at the time of diagnosis and at the first follow up visit when the chorioretinal scar formation was observed during the course of follow-up were summarized in Table 1. 
CLINICAL FINDINGS AND IMAGE ANALYSIS WITH MATLAB

\begin{tabular}{|c|c|c|c|c|c|c|c|c|c|c|}
\hline \multirow{4}{*}{$\begin{array}{l}\text { Eye } \\
\text { No., } \\
\text { Age, } \\
\text { Gender }\end{array}$} & \multirow{4}{*}{$\begin{array}{l}\text { Lesion } \\
\text { location }\end{array}$} & \multicolumn{3}{|l|}{ BCVA } & \multicolumn{3}{|c|}{ Active Lesion } & \multicolumn{3}{|c|}{ After Healing } \\
\hline & & \multirow{3}{*}{$\begin{array}{l}\text { At } \\
\text { baseline } \\
\text { (LogMar) }\end{array}$} & \multirow{3}{*}{$\begin{array}{l}\text { After } \\
\text { Healing } \\
\text { (LogMar) }\end{array}$} & \multirow{3}{*}{$\begin{array}{l}\text { Time of the } \\
\text { first visit } \\
\text { when } \\
\text { chorioretinal } \\
\text { scar was } \\
\text { detected } \\
\text { (Weeks) }\end{array}$} & \multirow[t]{3}{*}{$\begin{array}{l}\text { White } \\
\text { pixels }\end{array}$} & \multirow[t]{3}{*}{$\begin{array}{l}\text { Black } \\
\text { pixels }\end{array}$} & \multirow{3}{*}{$\begin{array}{l}\text { Black } \\
\text { pixel } \\
\text { index }\end{array}$} & \multirow[t]{3}{*}{$\begin{array}{l}\text { White } \\
\text { pixels }\end{array}$} & \multirow[t]{3}{*}{$\begin{array}{l}\text { Black } \\
\text { pixels }\end{array}$} & \multirow{3}{*}{$\begin{array}{l}\text { Black } \\
\text { pixel } \\
\text { index }\end{array}$} \\
\hline & & & & & & & & & & \\
\hline & & & & & & & & & & \\
\hline $1,20, F$ & Juxtapapillary & 0.10 & 0.0 & 4 & 15965 & 21131 & 0.569630 & 16107 & 20989 & 0.565802 \\
\hline $2,42, F$ & Juxtapapillary & 0.20 & 0.10 & 8 & 12193 & 30745 & 0.716032 & 26914 & 16024 & 0.373189 \\
\hline $3,19, F$ & Juxtapapillary & 0.20 & 0.10 & 10 & 21390 & 22478 & 0.472958 & 22478 & 18107 & 0.446150 \\
\hline $4,15, F$ & Peripheral & 0.20 & 0.0 & 8 & 16224 & 23137 & 0.665234 & 18736 & 20625 & 0.523996 \\
\hline $\begin{array}{l}5,20 \\
M\end{array}$ & Peripheral & 0.10 & 0.0 & 5 & 18476 & 16510 & 0.471903 & 20816 & 14170 & 0.405019 \\
\hline $6,21, F$ & Peripheral & 0.0 & 0.0 & 6 & 16068 & 25067 & 0.609380 & 19200 & 41135 & 0.466756 \\
\hline $7,31, \mathrm{~F}$ & Peripheral & 0.10 & 0.0 & 4 & 17562 & 16806 & 0.364752 & 24961 & 9407 & 0.273714 \\
\hline $8,35, F$ & Peripheral & 0.20 & 0.0 & 4 & 3256 & 39713 & 0.965420 & 4376 & 38593 & 0.898159 \\
\hline $9,30, F$ & Peripheral & 0.20 & 0.10 & 6 & 25013 & 12988 & 0.341780 & 34597 & 3404 & 0.089577 \\
\hline $\begin{array}{l}\text { 10,58, } \\
\mathrm{F}\end{array}$ & Macula & 0.0 & 0.0 & 8 & 14623 & 28158 & 0.642375 & 19582 & 23199 & 0.542273 \\
\hline $\begin{array}{l}11,24 \\
M\end{array}$ & Macula & 1.0 & 0.4 & 12 & 20400 & 22381 & 0.523153 & 21808 & 20973 & 0.490240 \\
\hline $\begin{array}{l}12,24 \\
M\end{array}$ & Macula & 0.0 & 0.0 & 16 & 19288 & 20234 & 0.511968 & 20540 & 18982 & 0.480289 \\
\hline $\begin{array}{l}13,9 \\
M\end{array}$ & Macula & 1.0 & 1.0 & 12 & 9987 & 28014 & 0.737191 & 15958 & 22043 & 0.580064 \\
\hline $\begin{array}{l}14,59, \\
F\end{array}$ & Macula & 1.0 & 0.4 & 16 & 10008 & 25941 & 0.721606 & 17752 & 18197 & 0.506189 \\
\hline
\end{tabular}

\section{Quantitative analysis between the baseline and final measurement of the chorioretinal lesion}

In all eyes, there was a statistically significant decrease in the black pixel countings at the final follow-up that was more prominent in the peripheral chorioretinal lesions. The least change was observed in the macular lesions. The percentage of black pixel reduction in macular lesions was significantly correlated with the poor visual acuity $(r=0.56$ and $p<0.001)$. There was no statistically significant difference between the percentage of black pixel reduction in patients with macular lesions on steroids when compared to patients with peripheral or peripapillary lesions not on steroids $(p=0.489)$. Table 2 summarizes the quantitative pixel analysis results at the baseline and at the time when the the scar formation was first observed in lesions with different locations. 
Table 2

QUANTITATIVE IMAGE ANALYSIS AT THE BASELINE AND AFTER THE DETECTION OF SCAR FORMATION

\begin{tabular}{|c|c|c|c|c|c|c|c|}
\hline \multirow{3}{*}{ Location of lesions } & \multicolumn{4}{|c|}{ Black pixels } & \multicolumn{3}{|c|}{ Follow-up changes } \\
\hline & Baseline & After Healing & Baseline & After Healing & Change & $\%$ change & $P$ value \\
\hline & & & Pixel index & Pixel index & & & \\
\hline Macula & 24644 & 20669 & 0,634 & 0,521 & -3974 & $15,4 \%$ & 0.032 \\
\hline Juxtapapillary & 23690 & 18373 & 0,586 & 0,462 & -5317 & $18,1 \%$ & 0.028 \\
\hline Peripheral & 22216 & 16954 & 0,551 & 0,427 & -5262 & $31,6 \%$ & 0.043 \\
\hline Total & 23572 & 18850 & 0,594 & 0,474 & -4722 & $21,8 \%$ & 0.001 \\
\hline
\end{tabular}

\section{Discussion}

OCTA is a non-invasive, volumetric diagnostic technique that uses the motion of red blood cells against static tissue to provide a highresolution blood flow information by transforming them to retinal and choroidal angiographic images. Thereby, retinal and choroidal vascular structures and the disease related changes can elaborately be assessed with the help of OCTA [12]. OCTA findings in toxoplasma retinochoroiditis has been studied in several papers previously. [13-17]. Park et al.[14] in a case, detected many collateral vascular branches surrounding the lesion and diffuse choroidal dilation at four weeks after commencing the treatment. Azar et al.[17] prospectively looked for the OCTA changes in 23 eyes of 23 patients with active and quiescent ocular toxoplasmosis. In active lesions, OCTA showed an extensive,well-delineated area of intense hyposignal in the parafoveal deep capillary plexus. Signals of decreased deep capillary density and disorganization were also observed in the choroid. In inactive lesions, OCTA demonstrated a homogenous and equally attenuated grayish hyposignal of the superficial and deep capillary plexi and a partial restoration of the nonperfused choroidal areas. de Oliveira Dias et al.[13] studied the 15 eyes of 15 patients with active toxoplasmic retinochoroiditis at baseline and after at least four weeks of follow up with SS-OCTA. At baseline, SS-OCTA showed no OCTA decorrelation signal next to the lesion site in all eyes and flow signal improvement was noted following the treatment. Three eyes presented with intraretinal vascular abnormalities during the follow up. Moreover, SS-OCTA showed retinal neovascularization in one eye and a presumed subclinical choroidal neovascular membrane in another eye.

We decided to see whether the improvement of active lesion size can be measured with OCTA techniques or not? Based on our previous experiences, CC slab seems to be the most informative slab to judge the borders of the lesion as the lesion stands out as a dark area with a relatively well-defined border when compared to other OCTA slabs. We measured the percentage of improvement in active toxoplasma retinochoroiditis lesion size on CC slabs. The non-detectable signal area corresponding to the lesion can be related to hypoperfusion or nonperfusion [17, 18]. Park et al[14] argued that the area charactherized with the non-detectable signal was the shadowing effect of inflammatory cell infiltration in association with diffuse choroidal dilatation. In our study, a mean of $21,8 \%$ size reduction was calculated at the time when the lesion became inactive as compared to the baseline lesion size with the image analysis. Surprisingly, the reduction in percentantage was $15.4 \%$ in eyes with macular lesion while the improvement in percentage was $31.6 \%$ in eyes with peripheral lesion and $18.1 \%$ in eyes with juxtapapillary lesion despite the addition of oral steroids to the antibiotic combination in patients with macular lesions. This result was somewhat contradictory to the previous reports stating that steroid adddition could limit the extention of the lesion. $[19,20]$ Retinochoroidal damage in toxoplasma retinochoroiditis has been attributed to the intraocular inflammation that occurs due to tissue damage caused by the organism. Therefore, it is suggested that corticosteroids, due to their anti-inflammatory effects, could be useful for limiting the inflammation in patients with acute ocular toxoplasmosis [21]. The main indications for the use of adjunctive systemic corticosteroids have been reported as severe vitreous haze, poor visual acuity, proximity of lesions to the fovea or optic disc and the large active lesion [22].Animal studies have revealed that systemic corticosteroids can be a useful additional medication to minimize the retinochoroidal damage [19, 20]. Chodos et al.[23] reported that the extention of lesion in patients receiving adjunctive corticosteroid therapy was more limited than in patients not receiving corticosteroid therapy without classifying according to lesion location [23]. Besides achieving less decrease in lesion size measured with the image analysis, eyes with macular lesions had also a worse visual prognosis than the peripheral and juxtapapillary lesions in our group of patients as reported before[17].

This study has several limitations. First, the study was in retrospective nature with a relatively small number of patients. Second, segmentation and the image analysis could be affected by the masking effect of the active inflammation. Third, the timing for the

Page 6/10 
analysis of scar was decided by the clinician and thereby it could be suggested that final shrinkage of the scar size could not be estimated properly. Fourth, the sample size was inadequate to reach a conclusion on the effect of additional oral corticosteroids on the final scar size.

With the development in OCTA technology and image analysis techniques we feel that as a noninvasive diagnostic technique OCTA can be an useful addition to our currently used diagnostic methods for the evaluation of retinal and choroidal vascular changes occurred during the acute and chronic stages of toxoplasma retinochoroiditis. With further development in OCTA technology and concurrent image analysis techniques we feel that new and clinically useful information can even be quantified during the healing of active toxoplasma retinochorioditis.

\section{Declarations}

Competing Interests: The authors report no conflicts of interest. The authors alone are responsible for the content and writing of the paper.

Funding Info: The authors declared that this study received no financial support.

Author contribution: All co-authors have contributed to the study, and all have read and approved the final version of the manuscript. Concept: A.O.S., M.K., Design: A.O.S., M.K., Data Collection or Processing: F.A., M.K., B.A., A.O.S., Analysis or Interpretation: M.K., B.A, T.T., A.S., F.A., Literature Search: F.A., A.O.S., B.A., M.K., Writing: F.A., M.K., A.O.S.

Data Availability: All data obtained during the study process were used in the study.

Animal Research (Ethics): There was no research on animals in this manuscript.

Consent to Participate (Ethics): Informed consent for participation was obtained from from all study patients.

Consent to Publish (Ethics): Informed consent for publication was obtained from all study patients.

Ethics approval: This study was conducted in accordance with the tenets of the Helsinki Declaration after obtaining the approval of local ethics committee (Dokuz Eylül University: 2021/04-01).

\section{References}

1. Yalcindag FN, Ozdal PC, Ozyazgan Y, et al (2018) Demographic and Clinical Characteristics of Uveitis in Turkey: The First National Registry Report. Ocul Immunol Inflamm 26: 17-26 https://doi.org/10.1080/09273948.2016.1196714

2. Lujan BJ (2014) Spectral domain optical coherence tomography imaging of punctate outer retinal toxoplasmosis. Saudi J Ophthalmol 28: 152-156 https://doi.org/10.1016/j.sjopt.2014.03.010

3. Mathis T, Delaunay B, Favard C, Denis P, Kodjikian L (2020) Hyperautofluorescent Spots In Acute Ocular Toxoplasmosis: A New Indicator of Outer Retinal Inflammation. Retina 40:2396-2402 https://doi.org/10.1097//AE.0000000000002759

4. Yoshizumi MO (1976) Experimental Toxoplasma retinitis: a light and electron microscopical study. Arch Pathol Lab Med 100: 487490

5. Vainisi SJ, Campbell LH (1969) Ocular toxoplasmosis in cats. J Am Vet Med Assoc 154: 141-152

6. Dingerkus VLS, Munk MR, Brinkmann MP, et al (2019) Optical coherence tomography angiography (OCTA) as a new diagnostic tool in uveitis. J Ophthalmic Inflamm Infect 9: 10 https://doi.org/10.1186/s12348-019-0176-9

7. Yeo JH, Chung H, Kim JT (2019) Swept-Source Optical Coherence Tomography Angiography According to the Type of Choroidal Neovascularization. J Clin Med 8:1272 https://doi.org/10.3390/jcm8091272

8. Jabs DA, Nussenblatt RB, Rosenbaum JT, Standardization of Uveitis Nomenclature Working G (2005) Standardization of uveitis nomenclature for reporting clinical data. Results of the First International Workshop. Am J Ophthalmol 140: 509-516 https://doi.org/10.1016/j.ajo.2005.03.057

9. Holland G OCG, Belfort R Jr, Remington JS. Toxoplasmosis In: Pepose JS, Holland GN, Wilhelmus KR, (1996) Ocular Infection \& Immunity. St Louis, Missouri: Mosby-Year Book, Inc,:1183-1223 
10. Otsu N (1979) A Threshold Selection Method from Gray-Level Histograms. IEEE Transactions on Systems, Man, and Cybernetics 9 : 62-66 https://doi.org/10.1109/tsmc.1979.4310076

11. Cohen LM, Goldstein DA, Fawzi AA (2016) Structure-function Relationships in Uveitic Cystoid Macular Edema: Using En Face Optical Coherence Tomography to Predict Vision. Ocul Immunol Inflamm 24: 274-281 https://doi.org/10.3109/09273948.2015.1056535

12. Karti O, Saatci AO (2019) Optical Coherence Tomography Angiography in Eyes with Non-infectious Posterior Uveitis; Some Practical Aspects. Med Hypothesis Discov Innov Ophthalmol 8: 312-322

13. de Oliveira Dias JR, Campelo C, Novais EA, et al (2020) New findings useful for clinical practice using swept-source optical coherence tomography angiography in the follow-up of active ocular toxoplasmosis. Int J Retina Vitreous 6: 30 https://doi.org/10.1186/s40942-020-00231-2

14. Park JH, Lee SY, Lee EK (2019) Morphological characteristics of ocular toxoplasmosis and its regression pattern on swept-source optical coherence tomography angiography: a case report. BMC Ophthalmol 19: 199 https://doi.org/10.1186/s12886-019-1209-8

15. Leong BCS, Gal-Or O, Freund KB (2019) Optical Coherence Tomography Angiography of Retinal-Choroidal Anastomosis in Toxoplasmosis Chorioretinitis. JAMA Ophthalmol 137: e184091 https://doi.org/10.1001/jamaophthalmol.2018.4091

16. Spaide RF (2015) Volume Rendering of Optical Coherence Tomography Angiography Reveals Extensive Retinal Vascular Contributions to Neovascularization in Ocular Toxoplasmosis. Retina 35: 2421-2422 https://doi.org/10.1097/IAE.0000000000000721

17. Azar G, Favard C, Salah S, Brezin A, Vasseur V, Mauget-Faysse M (2020) Optical Coherence Tomography Angiography Analysis of Retinal and Choroidal Vascular Networks during Acute, Relapsing, and Quiescent Stages of Macular Toxoplasma Retinochoroiditis. Biomed Res Int 2020: 4903735 https://doi.org/10.1155/2020/4903735

18. Vezzola D, Allegrini D, Borgia A, et al (2018) Swept-source optical coherence tomography and optical coherence tomography angiography in acquired toxoplasmic chorioretinitis: a case report. J Med Case Rep 12: 358 https://doi.org/0.1186/s13256-0181902-x

19. Kaufman HE (1960) The effect of corticosteroids on experimental ocular toxoplasmosis. Am J Ophthalmol 50: 919-926 https://doi.org/10.1016/0002-9394(60)90344-5

20. Hofflin JM, Conley FK, Remington JS (1987) Murine model of intracerebral toxoplasmosis. J Infect Dis 155: 550-557 https://doi.org/10.1093/infdis/155.3.550

21. Oray M, Ozdal PC, Cebeci Z, Kir N, Tugal-Tutkun I (2016) Fulminant Ocular Toxoplasmosis: The Hazards of Corticosteroid Monotherapy. Ocul Immunol Inflamm 24: 637-646 D https://doi.org/10.3109/09273948.2015.1057599

22. Holland GN, Lewis KG (2002) An update on current practices in the management of ocular toxoplasmosis. Am J Ophthalmol 134: 102-114 https://doi.org/10.1016/s0002-9394(02)01526-x

23. Chodos JB, Habegger-Chodos HE (1961) The treatment of ocular toxoplasmosis with spiramycin. Arch Ophthalmol 65: 401-409 https://doi.org/10.1001/archopht.1961.01840020403014

\section{Figures}



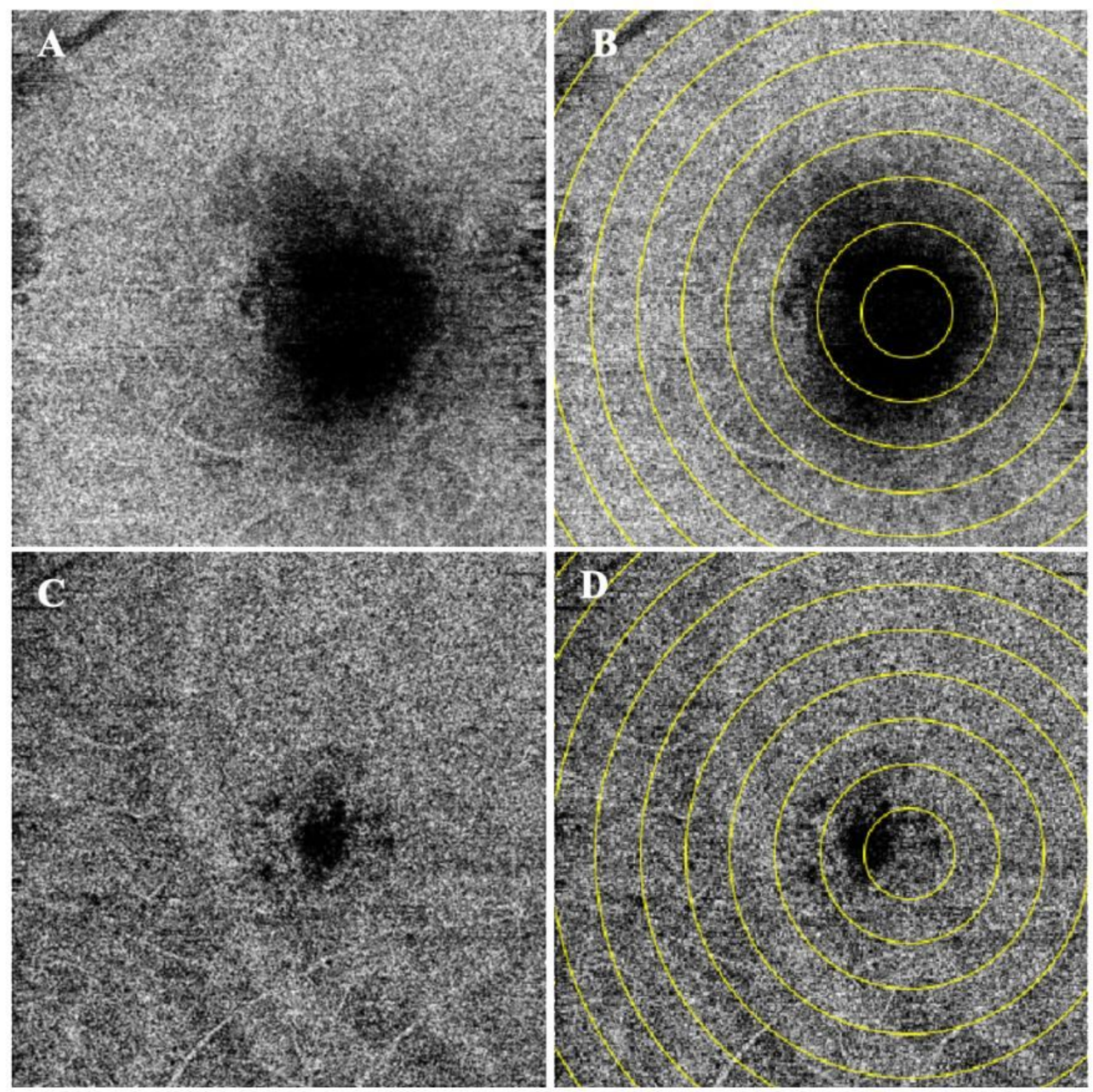

\section{Figure 1}

Choriocapillaris segmentation of optical coherence tomography angiography (OCTA) shows non-detectable signal areas at the site of the lesion and reduction of size of the lesion after healing (A-C). Black and white binarized image of acute and OCTA choriocapillaris segmentation image with superimposed concentric circles of increasing eccentricity from foveal lesion at baseline and after healing (BD). 


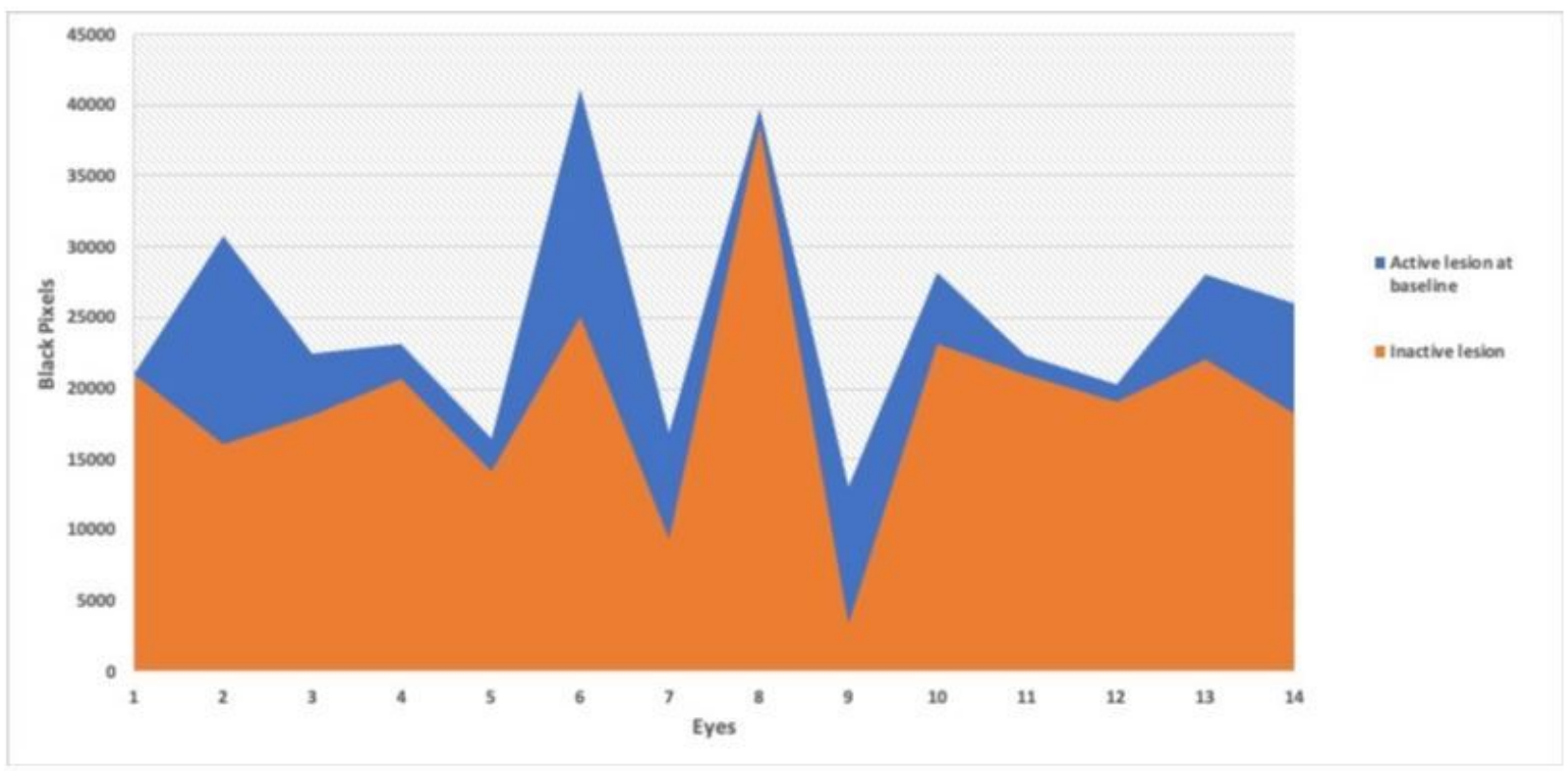

Figure 2

Change in black pixels active lesions at baseline and inactive lesion after healing. 